\title{
Ursolic Acid Exhibits Protective Property against DSS-induced Ulcerative Colitis in Mice through STAT3 Signaling Pathway
}

\author{
ZHUANG Qunchuan ${ }^{1,2,3,4}$, SHEN Aling ${ }^{2,3}$, LIU Liya ${ }^{2,3}$, SANKARARAMAN Senthilkumar ${ }^{5}$, \\ SFERRA Thomas Joseph ${ }^{5}$, CHEN Qi ${ }^{1,4^{*}}$, CHEN Youqin ${ }^{2,3,5^{*}}$ \\ ${ }^{1}$ Biomedical Research Center of South China, Fujian Normal University, Fuzhou, Fujian 350117, China; \\ ${ }^{2}$ Academy of Integrative Medicine, Fujian University of Traditional Chinese Medicine, Fuzhou, Fujian 350122, China; \\ ${ }^{3}$ Fujian Key Laboratory of Integrative Medicine in Geriatrics, Fujian University of Traditional Chinese Medicine, Fuzhou, Fujian 350122, \\ China: \\ ${ }^{4}$ Fujian Key Laboratory of Innate Immune Biology, Fujian Normal University, Fuzhou, Fujian 350117, China; \\ ${ }^{5}$ Department of Pediatrics, Case Western Reserve University School of Medicine, Rainbow Babies and Children's Hospital, Cleveland \\ 44106, OH, USA \\ *Correspondence: CHEN Qi, E-mail: nfsw@fjnu.edu.cn; CHEN Youqin, E-mail: yxc571@case.edu
}

Received 2020-11-12; accepted 2020-12-24

Foundation: The National Natural Science Foundation of China (81803882)

DOI: $10.3724 /$ SP.J.1329.2021.01005

开放科学(资源服务)标识码 $(\mathrm{OSID})$ :

\begin{abstract}
Objective: Anti-inflammatory effects of ursolic acid (UA) on a dextran sulfate sodium (DSS)-induced experimental murine colitis models was investigated to elucidate its possible molecular mechanisms on intestinal epithelial cells (IEC). Methods: For in vivo study, a total of 15 male BALB/c mice weighing (20-22) g were randomly divided into three groups: normal control group, DSS model group and DSS+UA treatment group; the mouse colitis model was induced by 3\% dextran sodium sulfate (DSS) for 8 days; one of the DSS-induced groups was pretreated with UA. The body weight and colon length of mice in each group were measured by physical balance and vernier caliper, respectively. The mice in each group were scored according to the clinical disease activity index (DAI) score method. HE staining was used to observe the histopathological changes of colon in each group. The changes of serum amyloid protease A (SAA) and IL-6 expression in colon tissue were measured by ELISA. Using IL-6-stimulated differentiated Caco-2 cells as an in vitro inflammatory model of human intestinal epithelium, the effects of UA on the activation of IL-6/signal transducer and activator of transcription 3 (STAT3) signal pathway in IEC were examined by Western blot for STAT3 phosphorylation. Results: 1) Compared with the normal control group, the DAI score was increased, the length of the colon was shortened, and the histological damage was obvious in the DSS model group $(P<0.05)$; administration of UA significantly reduced the severity of DSS-induced murine colitis as assessed by DAI score, colon length, and histology damage of colon $(P<0.05)$. 2) Compared with the normal control group, the SAA level and the IL-6 level of colon tissue in the DSS model group increased significantly. The DSS-induced increases of SAA and colonic IL-6 levels were reversed by UA treatment $(P<0.05)$. 3) Compared with normal IEC, IL-6 stimulation significantly increased the phosphorylation level of STAT3; STAT3 phosphorylation in IEC-treated with IL-6 and UA was significantly inhibited compared with only IL-6 stimulation $(P<0.05)$. Conclusion: Our findings implicate that UA ameliorates DSS-induced colonic inflammation by blocking IL-6/STAT3 signaling pathway, and therefore indicate that UA may have clinical potential as a novel targeted therapy for ulcerative colitis.
\end{abstract}

KEY WORDS ulcerative colitis; ursolic acid; inflammation; STAT3 signaling pathway; dextran sulfate sodium

\section{Introduction}

Inflammatory bowel disease (IBD) consists primari- ly of ulcerative colitis (UC) and Crohn's disease (CD). These disorders are chronic inflammatory conditions of the intestines and are characterized by the presence

\footnotetext{
引用格式: 庄群川, 沈阿灵,刘丽雅, 等. 熊果酸通过靶向 STAT3 信号通路对葡聚糖硫酸钠诱导的小鼠溃痰性结肠炎的保护作用 [J]. 康复学报, 2021,31(1):30-36. ZHUANG Q C,SHEN A L,LU L Y, et al. Ursolic acid exhibits protective property against DSS-induced ulcerative colitis in mice through STAT3 signaling pathway [J]. Rehabilitation Medicine, 2021, 31(1):30-36. DOI: $10.3724 /$ SP.J.1329.2021.01005
} 
in the gut of extensive areas of ulceration, pronounced inflammatory cell infiltrates, and epithelial cell necrosis $^{[1-3]}$. Though there has been rapid introduction of new therapies for IBD not all patients respond completely and the therapies are associated with side effects including immunosuppression. Thus, the development of new therapies with less toxicity is needed in the care of patients with IBD.

STAT3 is one of the signal transducer and activator of transcription (STAT) protein family members. The activation of STAT3 plays a major role in the pathophysiology of IBD ${ }^{[47]}$. STAT3 can be activated by a diverse group of growth factors and cytokines, including interleukin-6 (IL-6) ${ }^{[8]}$. STAT3 activation is mediated by phosphorylation at tyrosine 705 . The phosphorylation of cytosolic STAT3 induces its homodimerization, nuclear translocation, and DNA binding resulting in the expression of genes involved in inflammatory diseases such as IBD ${ }^{[9-12]}$. Previous studies have showed that IL-6 is elevated in serum of IBD patients and predicts clinical relapse in CD ${ }^{[13-15]}$ and anti-IL-6 therapy might have a therapeutic role ${ }^{[16-19]}$. Therefore, IL-6/STAT3 pathway is an appealing target for therapy in IBD.

Natural compounds have been used extensively for treating various inflammatory disorders. These compounds are especially sought out by and are useful for those who are unresponsive to or develop significant side effects with conventional treatments. Recently studies have suggested that a large group natural compound have the potential ability to limit the development and severity of certain cancers and inflammatory diseases ${ }^{[20-22]}$. A natural pentacyclic triterpenoid, ursolic acid (UA) has been reported to possess anti-inflammatory and antitumor properties ${ }^{[23-25]}$. Studies have shown that UA can block nuclear factor-kappaB (NF- $\mathrm{BB}$ )-mediated inflammatory signaling and suppress the phosphorylation of STAT3 ${ }^{[26-28]}$. However, it is unknown whether UA might have a therapeutic role in IBD. Thus, in the present study we explored the effect of UA in a well-established murine model of ulcerative colitis and elucidated its possible mechanism of action in an in vitro model of inflamed human intestinal epithelium.

\section{Materials and methods}

\subsection{Reagents, kits and antibodies}

Cell culture media and reagents were obtained from Invitrogen Thermofisher (Grand Island, NY, USA). Dextran sulfate sodium (DSS, molecular weight 40000 Da) was purchased from MP Biochemical (Solon, $\mathrm{OH}$, USA). Ursolic acid was purchased from Sigma Chemicals (St. Louis, MO, USA). Antibodies for Western blot were from Cell Signaling Technology (Danvers, MA,
USA). The immunoblot detection system (ECL Plus) was fromPierce (Rockford, IL, USA). Bicinchoninic acid (BCA) protein assay reagent was from Pierce (Rockford, IL, USA). Mouse-specific IL-6 ELISA kit was from Biolegend Inc. (San Diego, CA, USA). Mousespecific serum amyloid A (SAA) ELISA kit was from Immunology Consultants laboratory, Inc (Newberg, OR, USA). All the other chemicals, unless otherwise stated, were obtained from Sigma Chemicals (St. Louis, MO, USA).

\subsection{Preparation of UA stock solution}

UA was dissolved in DMSO $(10 \mathrm{mM})$ and stored at $-20{ }^{\circ} \mathrm{C}$ until used in the in vitro experiments. UA was freshly dissolved in saline for the animal experiments.

\subsection{Cell culture}

Human colon cancer Caco-2 cells were purchased from the American Type Culture Collection (Cat no. HTB37Rockville, MA, USA). The cells were maintained in Dulbecco's modified Eagle medium (DMEM) (Grand Island, NY, USA) containing $1,000 \mathrm{mg} / \mathrm{L}$ of glucose, and supplemented with $20 \%(\mathrm{v} / \mathrm{v})$ fetal bovine serum (FBS) (Thermofisher, Grand Island, NY, USA) and antibiotics $(50 \mathrm{U} / \mathrm{mL}$ penicillin and $50 \mu \mathrm{g} / \mathrm{mL}$ streptomycin), cultured at $37{ }^{\circ} \mathrm{C}$ in a humidified air containing $5 \% \mathrm{CO}_{2}$. Caco-2 cells usually reached confluence 3 days after seeding and differentiated into enterocyte-like cells 18-20 days post-confluence. The fully differentiated cells were used in the experiments. The media was changed every 2-3 days. The media was removed and supplemented with $0.5 \%$ FBS medium before the day of experiment.

\subsection{Induction of colitis and treatment with UA}

Male BALB/c mice (with an initial body weight of 20-22 g) were purchased from Shanghai SLAC Laboratory Animal Co., Ltd. (Shanghai, China). The mice were housed under pathogen-free conditions with a $12 \mathrm{~h}$ light/dark cycle and food and water were provided ad libitum throughout the experiments. The mice were acclimatized for 1 week prior to the experiment. The Institutional Animal Care and Use Committee of Fujian University of Traditional Chinese Medicine (Fuzhou, China) approved the animal experiments conducted in this study. Colitis was induced by administering 3\% DSS in the drinking water ad libitum from experimental day 1 through day 8 , as previously described ${ }^{[29]}$. Starting at the first day of induction of colitis, the mice were randomly divided into three groups $(n=5)$ : normal control group in which mice received neither DSS stimulation nor UA treatment; DSS model, or DSS+UA groups in which mice received DSS stimulation and intra-gastric administration of UA $(0.075 \mathrm{mg} / \mathrm{g})$ or the saline alone daily for 12 days.

\subsection{Evaluation of colitis}

The progression of DSS-induced colitis was moni- 
tored daily in a blinded manner. This included measurement of body weight, evaluation of stool consistency, and presence of blood in the stools by a guaiac paper test. Stool consistency was assessed using the following 3-point scale: 0, normal; 2, loose stools; and 4 , watery diarrhea. The intensity of the guaiac paper test was scored by the following scale: 0 , no bleeding; 2 , slight bleeding (+ occult test); and 4, gross bleeding (blood visible in stool or blood stains visible). Disease activity index (DAI) was represented as the sum of scores for weight loss, stool consistency and rectal bleeding, as previously described ${ }^{[21]}$.

\subsection{Sample collection}

At the end of the experiment, the mice were anesthetized with Avertin. Blood was collected via right heart ventricle puncture with lightly heparinized syringes and kept on ice. Sera were separated by $5 \mathrm{~min}$ centrifugation at $5,000 \times g$ and stored at $-80{ }^{\circ} \mathrm{C}$ prior to the analysis. After sacrifice, the colons were excised and length and weight were measured. One portion of each distal colon was dissected and fixed in $10 \%$ formalin for histological examination. The remainder of each distal colon was snap-frozen in liquid nitrogen and stored at $-80{ }^{\circ} \mathrm{C}$ for further analysis of the tissue IL-6 level.

\subsection{Assessment of histology}

The formalin fixed section of the distal colons were processed and stained with hematoxylin and eosin (H\&E). The severity of colitis was assessed in a blinded fashion by an experienced pathologist using a validated histological grading score of the colon as described previously ${ }^{[22]}$.

\subsection{Enzyme-linked immunosorbent (ELISA) as- say}

2.8.1 IL-6 level Proteins were extracted from the frozen colon using T-PER Tissue Protein Extraction Reagent Kit according to the manufacturer's instructions. Protein concentrations were determined by $\mathrm{BCA}$ protein assay kit (Rockford, IL, USA) and equal amounts of protein were utilized in triplicate for each condition. The concentrations of IL- 6 in the colons were measured using a mouse IL-6 ELISA kit (Biolegend) according to the manufacturers' instructions. All samples were assayed in triplicate. Absorbance was read at $450 \mathrm{~nm}$ using a microplate reader (model ELX800; BioTek Instruments, Inc., Winooski, VT, USA). Results are presented as mean (expressed in $\mathrm{pg} / \mathrm{mg}$ total protein) and standard deviations $(S D)$.

2.8.2 Serum amyloid A (SAA) level The concentrations of SAA in the sera were measured using a mouse SAA ELISA kit according to the manufacturer's instructions. All samples were assayed in triplicate. Absorbance was read at $450 \mathrm{~nm}$ using a microplate reader (model ELX800; BioTek Instruments, Inc., Winooski,
VT, USA). Results are presented as mean (expressed in $\mathrm{pg} / \mathrm{mL}$ ) and standard deviations $(S D)$.

\subsection{Western blot analysis}

Differentiated Caco-2 cells (20 days post-confluence) in 24-well bicameral inserts were pre-incubated with or without UA $(20 \mu \mathrm{M})$ for 1 hour prior to stimulation with IL-6 $(10 \mu \mathrm{g} / \mathrm{mL})$ by addition to the basolateral pole for 15 minutes. At the end of the experiment, cells were washed with ice cold phosphate-buffered saline (PBS) and lysed with mammalian cell lysis buffer (Thermofisher, Grand Island, NY, USA) containing protease and phosphatase inhibitor cocktails (Millipore, Bedford, MA, USA). The lysis buffer containing the disrupted cells was centrifuged at $11,000 \times \mathrm{g}$ at $4{ }^{\circ} \mathrm{C}$ for $10 \mathrm{~min}$ and the protein concentrations of the supernatant quantified with the BCA assay kit. Equivalent amounts of protein were resolved on $4 \%$ to $12 \%$ Novex Bis-Tris gels (NuPAGE; Grand Island, NY, USA). Proteins were then transferred into nitrocellulose membranes in the iBlot Western blot system (Invitrogen, Grand Island, NY, USA). The membranes were blocked for $1 \mathrm{~h}$ at room temperature with super Blocking Buffers (Pierce Biotechnology, Rockford, IL, USA) and incubated at $4{ }^{\circ} \mathrm{C}$ overnight with primary antibodies against pSTAT3 (rabbit, polyclonal, 1:1 000, CST, 9145), STAT3 (rabbit, polyclonal, 1:1 000, CST, 12640) and $\beta$-actin (rabbit, polyclonal, 1:2 000, CST, 4967) in blocking buffer. Following the primary antibody incubation period the membranes were washed and, subsequently, incubated with appropriate anti-rabbit IgG, HRP-linked secondary antibody (1:5 000, CST, 7074) for $1 \mathrm{~h}$ at room temperature. Membranes were analyzed using enhanced chemiluminescence Plus reagents and scanned with the Storm Scanner (Amersham Pharmacia Biotech Inc, NJ, USA).

\subsection{Statistical analysis}

Data are presented as the means \pm standard deviations $(S D)$ for the indicated number of independently performed experiments and analyzed using Student's $t$-test or one-way $A N O V A$, followed by $L S D$ 's test or Dunnett's test. Data were considered significant when $P<0.05$. All the analyses were performed using the SPSS package for Windows (version 22.0; SPSS, Inc., Chicago, IL, USA).

\section{Results}

\subsection{UA prevents clinical manifestations of DSS- induced ulcerative colitis in mice}

To evaluate whether UA can protect mice against DSS-induced ulcerative colitis, we first determined the clinical manifestations in experimental mice. Compared with the normal control group, DSS administration induced weight loss, higher disease activity index (DAI), and shortening of the colon (Fig. 1). However, 
in the DSS + UA group there was a significant amelioration of the weight loss and DAI as compared to DSS-induced group (Fig. 1A and Fig. 1B). Importantly, there was no significant difference in the body weight changes and clinical manifestations between normal control group and those mice receiving saline or UA only (data not shown).
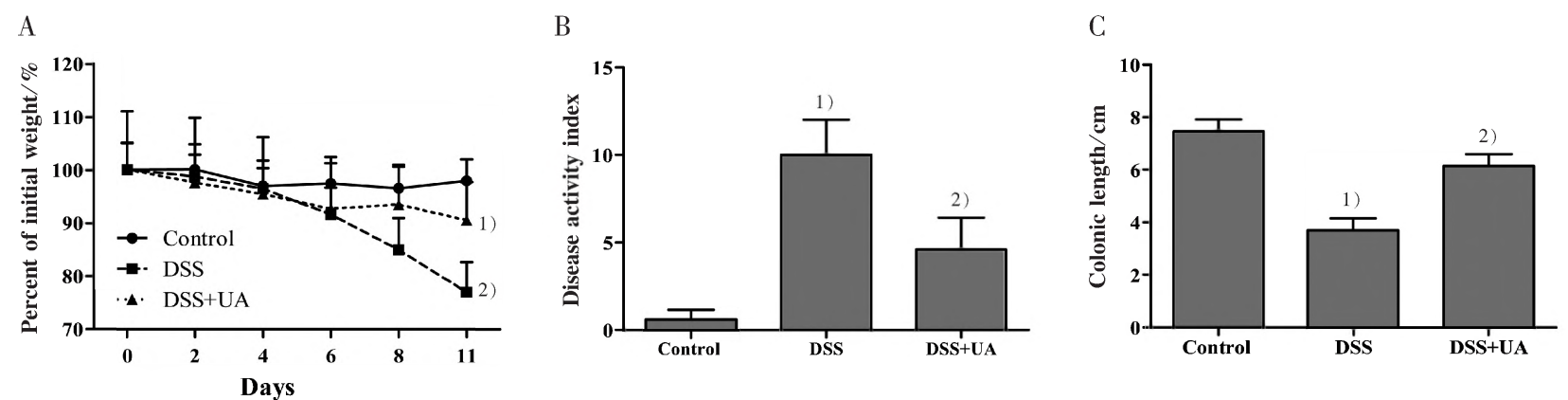

Note: Ulcerative colitis was induced in Balb/c mice by administering fresh tap water with 3\% DSS from day 1 to day for 8 days. Starting at the first day of induction of colitis, the mice of DSS model and DSS + UA received DSS stimulation and were given intra-gastric administration with saline or UA $(0.075 \mathrm{mg} / \mathrm{g})$, respectively, daily for 12 days. The progression of DSS-induced colitis was daily monitored in a blinded manner. A. The weight change of each mouse was measured. B. The DAI was evaluated upon termination of the experiment in accordance with the scoring system. C. Colons were excised on day 12 and its length was measured. Data were presented as the means \pm standard deviations (SD) ( $n=5$ mice/group). 1) $P<0.05$ versus controls; 2) $P<0.05$ versus DSS+UA.

Figure 1 Effect of UA on the clinical manifestations in mice with DSS-induced colitis

\subsection{UA prevents the histological damage of colon} tissue in mice with DSS-induced ulcerative colitis

To determine whether the reduction in clinical manifestations induced by UA is associated with the prevention of colonic inflammation, the anatomy of and histopathological changes within the colon were assessed. The colon length shortening observed in the DSS treated mice was prevented in the group with DSS + UA (Fig. 1C). Histologic evaluation (Fig. 2), revealed the distal colons from normal control mice has normal colonic histology with an intact epitheli- um, well-defined gland lengths with no observable inflammation in the mucosa, whereas colon tissues of DSS only showed severe colonic histological damages, including destruction of crypt structure with loss of goblet cells, disruption of the epithelial layer and submucosal infiltration of inflammatory cells. Noticeably, UA treatment showed a significantly reduction in the colonic inflammation. All mice receiving saline only or UA only had normal histology of the colon (data not shown).

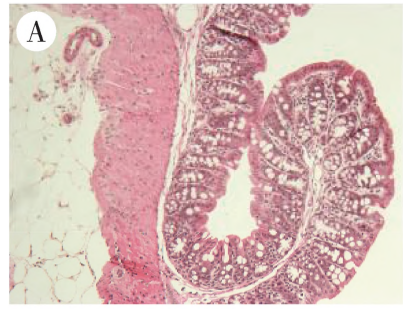

Control

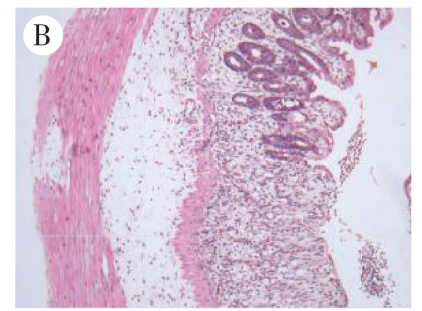

DSS

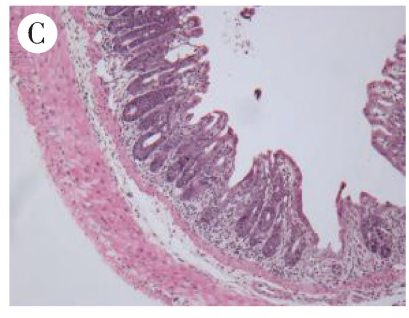

DSS+UA

Note: At the end of experiment, distal colonic samples were processed with H\&E staining. Histopathological changes were observed under the microscope. Images were captured at a magnification of $\times 100$.

Figure 2 Effect of UA on histopathological damage of colon in mice with DSS-induced colitis $(\times 100)$

\subsection{UA decreases the SAA level in mice with DSS- induced ulcerative colitis}

To further evaluate the inflammatory process in these mice, we measured the serum SAA. Consistent with the result from H\&E staining assay, DSS-induced elevation of SAA level was reduced by UA treatment (Fig.3). The SAA level in mice of normal control, DSS model, and DSS+UA group was $(292.1 \pm 61.7)$, (1 $427.3 \pm 452.8$ ), and $(444.5 \pm 172.8) \mu \mathrm{g} / \mathrm{mL}$, respectively $(P<0.05)$. 


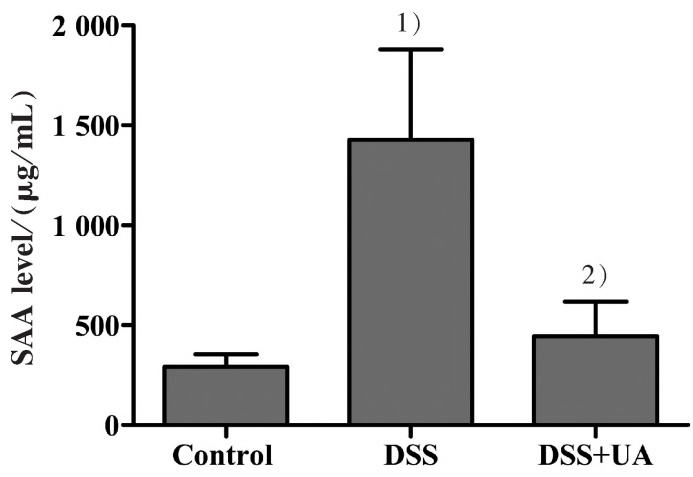

Note: Blood was collected at the end of experiment and the level of SAA was analyzed by ELISA. Data were presented as the means \pm standard deviations $(S D)(n=5$ mice/group). 1) $P<0.05$ versus controls; 2) $P<0.05$ versus DSS+UA.

Figure 3 Effect of UA on the level of serum amyloid A in mice with DSS-induced colitis

\subsection{UA Reduces IL-6 elevation within the colons} of mice with DSS-induced ulcerative colitis

To determine whether UA could reduce IL-6 levels within the colons of mice with induced ulcerative colitis, IL-6 ELISAs were performed on colon tissue protein extracts. UA treatment significantly decreased IL-6 levels in the colons of the DSS-induced mice (Fig. 4). The IL-6 levels in the normal control, DSS model, and DSS+UA group were $(320.509 \pm 78.651),(1638.707 \pm$ $296.850)$ or $(629.720 \pm 188.210) \mathrm{pg} / \mathrm{mg}$ total protein, respectively $(P<0.05)$.

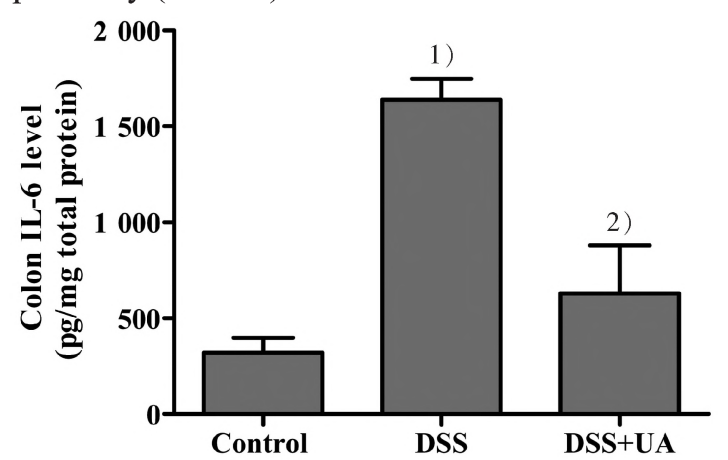

Note: Colons were excised at the end of experiment and the level of IL- 6 was analyzed by ELISA. Data were presented as the means \pm standard deviations $(S D)(n=5$ mice/ group). 1) $P<0.05$ versus controls; 2) $P<0.05$ versus DSS+UA.

Figure 4 Effect of UA on colonic IL-6 levels in mice with DSS-induced colitis

\subsection{UA inhibits IL-6-induced STAT3 phospho-} rylation in Caco-2 cells

According to the results in vivo, related mechanisms were subsequently explored in vitro. Since the role of IL-6/STAT3 pathway is the best-characterized signal pathway in inflammatory response, we further examined whether the possible mechanism of the effect of
UA on DSS-induced colitis by inhibiting IL-6-induced STAT3 phosphorylation. Using IL-6-stimulated differentiated Caco-2 cells as an in vitro inflammatory model of human intestinal epithelium, we examined the effects of UA on IL-6/STAT3 pathway. As shown in Fig. $5 \mathrm{~A}$ and $\mathrm{B}, \mathrm{IL}-6$-induced an increase in the expression of phosphorylated STAT3 in Caco-2 cells. However, UA treatment significantly inhibited this effect. The expression of non-phosphorylated STAT3 remained unchanged after the treatment with IL-6 and/or UA.

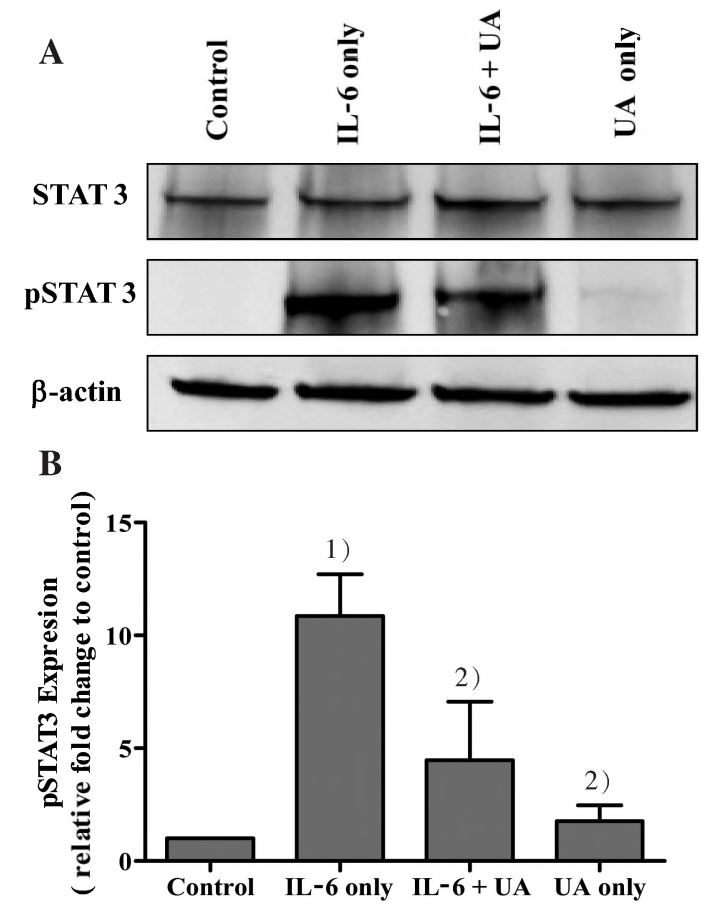

Note: The differentiated cells were pre-treated with UA for 2 hours and $10 \mathrm{ng} / \mathrm{mL}$ of IL- 6 was by added for $30 \mathrm{~min}$ utes. STAT3 phosphorylation was determined by western blot analysis using an antibody that recognizes phosphorylated STAT3 at Tyr705. $\beta$-actin was used as the internal control. A. Images were representative of three independent experiments. B. The integrated densities of the pSTAT3 and STAT3 bands were individually normalized to $\beta$-actin band using ImageJ software. The relatively reduced or increased levels of pSTAT3 and STAT3 were compared with the DMSO control, which was set as 1.00. Data were presented as the means \pm standard deviations $(S D)$. 1) $P<0.05$ versus controls; 2) $P<0.05$ versus DSS+UA.

Figure 5 Effect of UA on IL-6 induced STAT3 phosphorylation in Caco-2 cells

\section{Discussion}

Despite recent advance in the drug for treatment of IBD, important question about limited the use of these drugs is their toxicity. Recently research has focused on natural products as alternative agents that may be equally or more effective, but toxicity-free. UA ap- 
pears to have pharmacological effects combined with low toxicity ${ }^{[30-31]}$. Previous studies in vitro and in vivo have demonstrated that UA has biological effects, such as anti-oxidative, anti-inflammation, and an-ticancer activities ${ }^{[23,25-28]}$. However, there is limited data available evaluated whether UA has an effect on colonic inflammation. In the present study, we first examined the effects of UA on an experimental model of DSSinduced colitis that is a commonly used model for the inflammation component of IBD. Colitis was characterized by weight loss, increased disease activity index, shortened colon length, microscopic inflammation, and increases in serum SAA. In our study, for the first time, we demonstrated that UA has therapeutic efficacy in this model of colitis ameliorating each of these effects.

IL-6 is a cytokine secreted by lamina propria cells in patients with IBD. In patients with IBD serum IL-6 levels positively correlate with severity of intestinal histopathology ${ }^{[1416]}$. Previous studies in mice have demonstrated that the colonic expression of IL-6 is increased in acute colitis ${ }^{[32-33]}$. In the present study, we observed the increased level of IL-6 in the distal colon of mice with DSS-induce colitis, providing supporting evidence for the crucial role of IL-6 in colonic inflammation. Moreover, UA significantly inhibited the production of IL-6 in this model.

In general, IL-6 binds to soluble or membranebound IL-6 receptors (e.g., sIL-6Ra or IL-6Ra) resulting in the activation of Janus kinase 2 (JAK2) and the downstream effectors signal transducer and activator of STAT3 and phosphatidyl inositol 39 kinase $^{[34-35]}$. Recent studies have demonstrated a beneficial effect of anti-IL-6 therapy in Crohn's disease as well as in animal models of colitis ${ }^{[18-19]}$. These data strongly suggested that activation of the IL-6/STAT3 pathway has a key role in the development of IBD and the prevention of activation of this pathway maybe useful in the treatment of IBD. Previous reports have demonstrated that UA down-regulates activation of various pro-inflammatory pathways including NF- $\mathrm{B}, \mathrm{STAT} 3, \mathrm{AKT}$, and IKK $\alpha / \beta$ phosphorylation ${ }^{[26-28]}$. Therefore, UA's anti-inflammatory effect on colitis may through the inhibition of STAT3 phosphorylation. To confirm this hypothesis, we investigated STAT3 activation in IL-6 stimulated Caco-2 cells. Our results indicate that UA strongly suppresses STAT3 phosphorylation and this might be the possible mechanism for its anti-inflammatory action in UC.

In conclusion, our present study demonstrates that UA attenuates intestinal inflammation in the experimental murine colitis model and may mediate this through the inhibition of activation of the IL-6/STAT3 pathway. These findings provide, for the first time, the novel protective effect of UA against inflammation in the colon. The present study suggests that further studies should focus on the clinical development of UA for the treatment of IBD.

\section{References}

[1] PODOLSKY D K. Inflammatory bowel disease [J]. N Engl J Med, 2002, 347: 417-429.

[2] MALOY K J, POWRIE F. Intestinal homeostasis and its breakdown in inflammatory bowel disease [J]. Nature, 2011, 474: 298306.

[3] KASER A, ZEISSIG S, BLUMBERG R S. Inflammatory bowel disease $[\mathrm{J}]$. Annu Rev Immunol, 2010, 28: 573-621.

[4] DABRITZ J, JUDD L M, CHALINOR H V, et al. Altered gp 130 signaling ameliorates experimental colitis via myeloid cell-specific STAT3 activation and myeloid-derived suppressor cells [J]. Sci Rep, 2016, 6: 584.

[5] GRIVENNIKOV S, KARIN E, TERZIC J, et al. IL-6 and Stat3 are required for survival of intestinal epithelial cells and development of colitis-associated cancer [J]. Cancer Cell, 2009, 15: $103-113$.

[6] HAN, THEISS A L. Stat3: friend or foe in colitis and colitisassociated cancer? [J]. Inflamm Bowel Dis, 2014, 20: 2405-2411.

[7] ANDJAR I, RECIO M C, GINER R M, et al. Inhibition of ulcerative colitis in mice after oral administration of a polyphenolenriched cocoa extract is mediated by the inhibition of STAT1 and STAT3 phosphorylation in colon cells [J]. J Agric Food Chem, 2011, 59: 6474-6483.

[8] HODGE D R, HURT E M, FARRAR W L. The role of IL-6 and STAT3 in inflammation and cancer [J]. Eur J Cancer, 2005, 41: 2502-2512.

[9] ZHANG J, WU J, PENG X, et al. Associations between STAT3 rs744166 polymorphisms and susceptibility to ulcerative colitis and Crohn's disease: a meta-analysis [J]. PLos One 2014, 9 (10): e109625.

[10] WELTE T, ZHANG S S, WANG T, et al. STAT3 deletion during hematopoiesis causes Crohn's disease-like pathogenesis and lethality: a critical role of STAT3 in innate immunity [J]. Proc Natl Acad Sci USA, 2003, 100: 1879-1884.

[11] BACKERT I, KORALOV S B, WIRTZ S, et al. STAT3 activation in Th17 and Th22 cells controls IL-22-mediated epithelial host defense during infectious colitis [J]. J Immunol, 2014, 193: 3779-3791.

[12] WILLSON T A, JURICKOVA I, COLLINS M, et al. Deletion of intestinal epithelial cell STAT3 promotes T-lymphocyte STAT3 activation and chronic colitis following acute dextran sodium sulfate injury in mice [J]. Inflamm Bowel Dis, 2013, 19: 512525 .

[13] HYAMS J S, FITZGERALD J E, TREEM W R, et al. Relationship of functional and antigenic interleukin 6 to disease activity in inflammatory bowel disease [J]. Gastroenterology, 1993, 104: 1285-1292.

[14] VANKEMSEKE C, BELAICHE J, LOUIS E. Frequently relapsing Crohn's disease is characterized by persistent elevation in interleukin -6 and soluble interleukin -2 receptor serum levels during remission $[\mathrm{J}]$. Int J Colorectal Dis, 2000, 15: 206-210.

[15] NEURATH M F. Cytokines in inflammatory bowel disease $[\mathbf{J}]$. Nat Rev Immunol, 2014, 14: 329-342.

[16] DANESE S, VERMEIRE S, HELLSTERN P, et al. Randomised trial and open-label extension study of an anti-interleukin-6 antibody in Crohn's disease (ANDANTE I and II) [J]. Gut, 2019, 68: $40-48$.

[17] ITO H, TAKAZOE M, FUKUDA Y, et al. A pilot randomized trial of a human anti-interleukin -6 receptor monoclonal antibody in active Crohn's disease [J]. Gastroenterology, 2014, 126: 989-996.

[18] NEURATH M F. New targets for mucosal healing and therapy in inflammatory bowel diseases [J]. Mucosal Immunol, 2014, 7: 6-19.

[19] NEURATH M F. Current and emerging therapeutic targets for IBD [J]. Nat Rev Gastroenterol Hepatol, 2017, 14: 269-278.

[20] SIVEEN K S, SIKKA S, SURANA R, et al. Targeting the STAT3 signaling pathway in cancer: role of synthetic and natural in- 
hibitors [J]. Biochim Biophys Acta, 2014, 1845: 136-154

[21] SALEHI B, STOJANOVIC-RADIC Z, MATEJIC J, et al. The therapeutic potential of curcumin: A review of clinical trials [J]. Eur J Med Chem, 2019, 163: 527-545.

[22] TASNEEM S, LIU B, LI B, et al. Molecular pharmacology of inflammation: Medicinal plants as anti-inflammatory agents $[\mathrm{J}]$. Pharmacol Res, 2019, 139: 126-140.

[23] YIN R, LI T, TIAN J X, et al. Ursolic acid, a potential anticancer compound for breast cancer therapy [J]. Crit Rev Food Sci Nutr, 2018, 58: 568-574.

[24] HUSSAIN H, GREEN I R, ALI I, et al. Ursolic acid derivatives for pharmaceutical use: a patent review $(2012-2016)[\mathrm{J}]$. Expert Opin Ther Pat, 2017, 27: 1061-1072.

[25] ZHAO J, ZHENG H, SUI Z, et al. Ursolic acid exhibits antiinflammatory effects through blocking TLR4-MyD88 pathway mediated by autophagy $[\mathrm{J}]$. Cytokine, 2019, 123: 154726.

[26] FONTANA G, BRUNO M, NOTARBARTOLO M, et al. Cytotoxicity of oleanolic and ursolic acid derivatives toward hepatocellular carcinoma and evaluation of $\mathrm{NF}-\mathrm{kB}$ involvement $[\mathrm{J}]$. Bioorg Chem, 2019, 90: 103054.

[27] PENG J, REN X, LAN T, et al. Renoprotective effects of ursolic acid on ischemia/reperfusion-induced acute kidney injury through oxidative stress, inflammation and the inhibition of STAT3 and NF- $\mathrm{KB}$ activities [J]. Mol Med Rep, 2016, 14: 3397-3402.

[28] MA J Q, DING J, XIAO Z H, et al. Ursolic acid ameliorates carbon tetrachloride-induced oxidative DNA damage and inflammation in mouse kidney by inhibiting the STAT3 and NF$\kappa B$ activities $[\mathrm{J}]$. Int Immunopharmacol, 2014, 21: 389-395.
[29] LI L, SHEN A, CHU J, et al. Pien Tze Huang ameliorates DSS induced colonic inflammation in a mouse colitis model through inhibition of the IL-6/STAT3 pathway [J]. Mol Med Rep, 2018, 18: $1113-1119$

[30] NOVOTNY L, VACHALKOVÁ A, BIGGS D. Ursolic acid: an antitumorigenic and chemopreventive activity $[\mathrm{J}]$. Minireview. Neoplasma, 2001, 48: 241-246.

[31 ] HUSSAIN H, GREEN I R, ALI I, et al. Ursolic acid derivatives for pharmaceutical use: a patent review $(2012-2016)[J]$. Expert Opin Ther Pat, 2017, 27: 1061-1072.

[32] LEE M J, LEE J K, CHOI J W, et al. Interleukin-6 induces S100A9 expression in colonic epithelial cells through STAT3 activation in experimental ulcerative colitis $[\mathrm{J}]$. PLoS One, 2012, 7: e38801.

[33 ] YAMAMOTO M, YOSHIZAKI K, KISHIMOTO T, et al. IL-6 is required for the development of Th1 cell-mediated murine colitis [J]. J Immunol, 2000, 164: 4878-4882.

[34] WANG Y, VAN BOXEL-DEZAIRE A H, CHEON H, et al. STAT3 activation in response to IL-6 is prolonged by the binding of IL-6 receptor to EGF receptor $[\mathrm{J}]$. Proc Natl Acad Sci U S A, 2013, 110: 16975-16980.

[35] MATSUMOTO S, HARA T, MITSUYAMA K, et al. Essential roles of IL -6 trans-signaling in colonic epithelial cells, induced by the IL-6/soluble-IL-6 receptor derived from lamina propria macrophages, on the development of colitis-associated premalignant cancer in a murine model $[\mathrm{J}]$. J Immunol, 2010, 184: $1543-1551$.

\section{熊果酸通过靶向 STAT3 信号通路对葡聚糖硫酸钠 诱导的小鼠溃疡性结肠炎的保护作用}

庄群川 ${ }^{1,2,3,4}$, 沈阿灵 ${ }^{2,3}$, 刘丽雅 ${ }^{2,3}$, SANKARARAMAN Senthilkumar ${ }^{5}$, SFERRA Thomas Joseph ${ }^{5}$, 陈 骐 ${ }^{1,4^{*}}$, 陈友琴 $2,3,5^{*}$

1 福建师范大学南方生物医学研究中心, 福建 福州 350117 ;

2 福建中医药大学中西医结合研究院, 福建 福州 350122 ;

3 福建省中西医结合老年性疾病重点实验室, 福建 福州 350122;

4 福建省天然免疫生物学重点实验室, 福建 福州 350117 ;

5 凯斯西储大学医学院儿科系,美国, 俄克拉荷马克利夫兰, 44106

*通信作者:陈骐,E-mail: nfsw@fjnu.edu.cn;陈友琴,E-mail: yxc571@ease.edu

摘要目的: 研究熊果酸(UA) 对葡聚糖硫酸钠 (DSS)诱导的实验性小鼠结肠炎模型的抗炎作用, 旨在阐明 其对肠上皮细胞 (IEC) 作用的可能分子机制。方法: 在体内研究中, 将体质量为 $20 \sim 22 \mathrm{~g}$ 的雄性 BALB/c 小 鼠 15 只采用随机数字表法分为正常对照组、DSS 模型组、DSS+熊果酸治疗组。通过 $3 \%$ DSS 诱导 $8 \mathrm{~d}$, 制备 小鼠结肠炎模型; 其中一组 DSS 诱导的小鼠结肠炎模型采用UA 预处理。各实验组的小鼠体质量和结肠长 度分别采用物理天平和游标卡尺测定; 参照临床疾病活动指数 (DAI) 评分法对小鼠进行评分。采用 HE 染色 观察各组结肠组织病理学变化; 通过 ELISA 法测定各组小鼠血液中血清淀粉样蛋白酶 A 和结肠组织中 IL-6 的水平。以 IL-6 刺激分化的 Caco-2 细胞制备体外人肠上皮细胞炎症模型, 通过 Western blot 检测 UA 对肠 上皮细胞 IL-6/STAT3 信号通路中 STAT3 磷酸化的影响。结果: (1) 与正常对照组比较, DSS 模型组的 DAI 评分增加、结肠长度缩短和组织损伤明显, 差异均具有统计学意义 $(P<0.05)$; 与 DSS 模型组比较, UA 显著 抑制了 DSS 诱导的 DAI 评分增加、结肠长度缩短和组织学损伤, 差异均具有统计学意义 $(P<0.05)$ 。(2) 与正 常对照组比较, DSS 模型组的血清淀粉酶 (SAA) 水平和结肠组织中 IL-6 水平升高明显, 差异均具有统计学 意义 $(P<0.05)$; 与 DSS 模型组比较, UA 可显著逆转 DSS 诱导的血清淀粉酶 (SAA) 水平和结肠 IL-6 水平的 升高, 差异均具有统计学意义 $(P<0.05)$ 。(3) 与正常肠上皮细胞比较, IL-6 刺激显著上调 STAT3 的磷酸化水 平; 而UA 可显著抑制肠上皮细胞中 IL-6 诱导的 STAT3 磷酸化水平的增加, 差异具有统计学意义 $(P<0.05)$ 。 结论: 熊果酸可通过阻断 IL-6/STAT3 信号通路改善了 DSS 诱导的结肠炎, 提示熊果酸在茧向治疗溃病性 结肠炎中可能具有临床应用潜力。

关键词溃疡性结肠炎; 熊果酸; 炎症; STAT3 信号通路; 葡聚糖硫酸钠

DOI : $10.3724 /$ SP.J.1329.2021.01005 